\title{
Plagiarism detection and prevention: a primer for researchers
}

\author{
Olena Zimba ${ }^{10}$, Armen Yuri Gasparyan² ${ }^{10}$ \\ ${ }^{1}$ Department of Internal Medicine No. 2, Danylo Halytsky Lviv National Medical University, Lviv, Ukraine \\ 2Departments of Rheumatology and Research and Development, Dudley Group NHS Foundation Trust (Teaching Trust of the University \\ of Birmingham, UK), Russells Hall Hospital, Dudley, West Midlands, UK
}

\begin{abstract}
Plagiarism is an ethical misconduct affecting the quality, readability, and trustworthiness of scholarly publications. Improving researcher awareness of plagiarism of words, ideas, and graphics is essential for avoiding unacceptable writing practices. Global editorial associations have publicized their statements on strategies to clean literature from redundant, stolen, and misleading information. Consulting related documents is advisable for upgrading author instructions and warning plagiarists of academic and other consequences of the unethical conduct. A lack of creative thinking and poor academic English skills are believed to compound most instances of redundant and "copy-and-paste" writing. Plagiarism detection software largely relies on reporting text similarities. However, manual checks are required to reveal inappropriate referencing, copyright violations, and substandard English writing.

Medical researchers and authors may improve their writing skills and avoid the same errors by consulting the list of retractions due to plagiarism which are tracked on the PubMed platform and discussed on the Retraction Watch blog.
\end{abstract}

Key words: plagiarism, publishing, publication ethics, rheumatology.

\section{Introduction}

Plagiarism is one of the frequent forms of publication ethics violation. Researchers from all over the world may witness such a violation in their academic environment, and some of them may intentionally or unintentionally reuse their own or others' intellectual property without proper processing and crediting $[1,2]$.

Medical and allied health researchers are reminded that the Medical Subject Headings (MeSH) term defines plagiarism as "passing off as one's own the work of another without credit" (https://www.ncbi.nlm.nih. gov/mesh/?term=plagiarism). This term was introduced back in 1990. Since then, global understanding of plagiarism has evolved to reflect a variety of unethical reuses of ideas, texts, and graphical materials [3].

The global open access movement has made it possible to easily reveal most instances of plagiarism, including copying texts and graphics across digitized old and new sources. The resultant retractions of erroneous and otherwise unethical articles have predominantly affected biomedical authors from China, India and Iran, particularly those who publish in low-impact journals [4]. The digitization of editorial management and regular scanning of countless online platforms have enabled detection of unethical reuse in manuscripts undergoing peer review [5]. Peer review digitization has also allowed exposure of instances of stealing ideas and materials which are intended for confidential and privileged evaluation by reviewers [6].

Intellectual theft is increasingly viewed as a serious ethical transgression in countries entering the global academic competition and adjusting their research and development policies to the universally acceptable norms. The awareness of various forms of plagiarism is growing due to the international research cooperation and quality publishing that involve academics with various language and cultural traditions. However, the issue 
of plagiarism in the globalized world of science is complicated due to variably perceived definitions of the unethical conduct, recycling of one's own published materials, and unacceptable duplication of identical scientific information in different languages [7].

\section{Editorial guidance on plagiarism}

Global editorial recommendations contain a number of points instructing journal editors how to deal with suspected plagiarism and redundant/overlapping materials at pre- and post-publication stages. Core practices of the Committee on Publication Ethics (COPE) encourage editors to define plagiarism in their instructions and explicitly guide readers on how to reuse their published articles [8]. Also, all authors of manuscripts and published articles with misappropriation of intellectual property should be aware of their full responsibility for any wrongdoing at any stage. In case of suspicion, editors may question all co-authors and related authorities [9].

The Council of Science Editors (CSE) defines piracy and plagiarism as related violations of publication ethics with unauthorized reproduction of ideas, data, methods, and graphical materials, including those of the plagiarist (self-plagiarism and duplicate publication) [10]. Plagiarism, falsification, and fabrication are viewed by the CSE as different forms of research misconduct which may justify academic sanctions imposed by relevant national bodies and professional societies. To avoid any accusations of plagiarism, authors need to properly process primary literature and credit generators of ideas and other intellectual properties. Editors, in turn, should be skilled to identify copied and redundant materials by using advanced software and various other means.

Finally, the World Association of Medical Editors (WAME) reaffirms editorial intolerance of plagiarism in unpublished and published manuscripts and proposes to treat self-plagiarism differently, particularly in the case of linguistically redundant description of methods and other inevitable and unintentional duplications [11].

\section{Creative thinking and plagiarism}

Plagiarism is often revealed in works of novice nonAnglophone authors who are exposed to a conservative educational environment that encourages copying and memorizing and rejects creative thinking $[12,13]$. The gaps in training on research methodology, ethical writing, and acceptable editing support are also viewed as barriers to targeting influential journals by medical students and graduates [14].

The ease of accessing quality online articles of experienced authors, unawareness of plagiarism, and uncertain research ethics policies may push researchers in some academic institutions to copy, recycle, and produce unethical publications $[15,16]$.

A large survey of Western and Eastern European Bachelor and Master degree students $(n=1757)$ revealed diametrically opposite approaches to increasing awareness of plagiarism and arranging anti-plagiarism courses, with Polish students lacking training in these fields [17]. Additionally, a survey of 1100 undergraduate medical students in Pakistan pointed to a high percentage of unawareness of plagiarism (87\%) and instances of plagiarism (71\%) [18]. Finally, a nationwide survey of 706 Iranian medical graduates and faculty members revealed that the majority of the surveyees (74\%) had not received any training on plagiarism [19]. The same survey revealed that $11 \%$ had not even heard about such an ethical transgression.

The existence of numerous editing and copying agencies preying on novice researchers, students, and authors may further complicate the issue and negatively affect scholarly publishing in China and some other nonAnglophone countries [9].

\section{Instances of plagiarism}

Several forms of plagiarism can be distinguished based on confounders of this misconduct (Table I). Depending on author intentions, plagiarism is classified into intentional and unintentional (accidental) forms [20]. The former is a deliberate unethical act aimed at misleading readers by skilled authors who steal ideas, texts, and graphics and present stolen materials as their own. Its detection is followed by academic sanctions and other punishments. The unintentional form may surface due to incorrectly paraphrasing and referencing previously published works [21].

Inexperienced authors are often blamed for such misconduct, involving unattributed copying of text passages, scientific facts, and others' ideas. Properly editing and referencing such manuscripts prior to journal submission and correcting erroneous articles by publishing apologies to readers could be sufficient in cases of unintentional plagiarism [22].

Experts distinguish plagiarism of ideas, words (texts), and images (graphics) [3]. Ideas can be stolen by unethical evaluators of grant projects, journal manuscripts, or other scholarly materials during the peer review, which is intentionally delayed to allow the plagiarist to publish his/her own article with misappropriated ideas first. Misappropriation of ideas and methodologies is a more serious and inconspicuous misconduct than copying of words [23].

Textual plagiarism manifests in various forms which can be detected by advanced search engines and software that analyze similarities across a sizeable amount of digitized publications. Direct, or word-for-word, and 
Table I. Common instances of plagiarism

\begin{tabular}{|c|c|}
\hline Ethical misconduct & Involved individuals \\
\hline Plagiarism of ideas & $\begin{array}{c}\text { Reviewers of scholarly works, researchers copying unpublished hypotheses, } \\
\text { published methodologies, and ideas }\end{array}$ \\
\hline Direct (verbatim) copying & Inexperienced authors who are unaware of plagiarism and copy texts with or without referencing \\
\hline Paraphragiarism & $\begin{array}{l}\text { Authors who copy text passages with or without referencing and then replace a few words with } \\
\text { synonyms, reshuffle words, sentences, and paragraphs to intentionally confuse anti-plagiarism software }\end{array}$ \\
\hline Text recycling & Authors and copyright holders who think that there is no problem to reuse their own intellectual property \\
\hline Translational plagiarism & $\begin{array}{l}\text { Authors who republish the same works in different languages without primary and secondary } \\
\text { publishers' knowledge and agreement }\end{array}$ \\
\hline Plagiarism of graphics & $\begin{array}{l}\text { Authors of reviews and other articles who reuse images, tables, and other graphical materials } \\
\text { without official permission and in violation of copyright }\end{array}$ \\
\hline $\begin{array}{l}\text { Plagiarism with citation } \\
\text { manipulation }\end{array}$ & Authors who cite nonexistent sources or manipulate citations to conceal substantive plagiarism \\
\hline Compound plagiarism & $\begin{array}{l}\text { Individuals (editing agents) embarking on stealing, translating, and editing published materials } \\
\text { to escape anti-plagiarism software red flags }\end{array}$ \\
\hline
\end{tabular}

translational forms of plagiarism are relatively easy to detect by employing search engines and anti-plagiarism software [24, 25]. Paraphrasing and patchwork plagiarism may confuse plagiarism detection systems by plagiarists' attempts to replace a few words in the original text and misappropriate phrases and sentences. Careful manual checks and analyses of keywords and references may help to correctly interpret the similarity reports generated by software.

Plagiarists may intentionally increase the list of references by citing non-existent sources or incorrectly cite primary sources taken from secondary ones (systematic reviews) with the sole aim of misleading readers and concealing plagiarism of secondary publications [20]. A form of manipulation ("Trojan citation") is also reported in connection with referring to relevant items to cover up substantive plagiarism and confuse journal editors and anti-plagiarism software [26].

Current anti-plagiarism software may detect unacknowledged recycled (self-plagiarized) texts, the socalled salami (data stemming from a single study spread across several papers) and augmented (opposite to salami) texts. Accusations of plagiarism in such cases require thorough manual checks of all similar parts, particularly by experts in the professional field.

Detecting identical abstracts requires special consideration due to the similarities of some full texts with congress abstracts and preprints, which are unpublished items and do not account for plagiarism. As such, authors should be advised to provide notes in their manuscripts, linking to previously posted congress abstracts and reposted preprints.

While concentrating on textual similarities, editors employing anti-plagiarism software often overlook graphical overlaps which may reveal compound forms of ethics violation and copyright infringement [27, 28]. Thorough graphical analyses are particularly required for manuscripts with tables, figures, depiction of technological processes, and chemical formulae [29]. Questioning authors about the authenticity of all materials, requesting official reuse permissions from copyright holders, and referencing primary sources of reused or modified graphics may help to avoid unethical conduct and copyright infringement [30].

With the advent of anti-plagiarism software, some journal editors set limits of minor, moderate, and unacceptable copying and text recycling. They argue that less than $10 \%$ of verbatim copying, particularly in Methods section, could be tolerated provided there are no linguistic options to paraphrase [31]. Accordingly, 15-20\% of textual overlap is judged as less tolerable and more than $30 \%$ as unacceptable. Although such a quantitative classification helps stratify anti-plagiarism measures, most experts advocate a zero tolerance policy since even a small percentage of copying may reveal complicated and concealed ethics violations [32].

\section{Plagiarism detection}

Researchers should be aware of what constitutes plagiarism and how to detect it (Table II). Those authors who master academic English, familiarize themselves with bibliographic searches, and advance their graphics designing skills may avoid most instances of plagiarism, duplication, and copyright infringement. Those who employ anti-plagiarism tools should combine software and human-detection options.

Although none of the currently available anti-plagiarism systems is perfect [33], overlooking the importance of related editorial checks may affect the authenticity 
Table II. Strategies for plagiarism detection

\begin{tabular}{|c|c|c|}
\hline Processed items & Detection strategies & Detecting tools and individuals \\
\hline Text passages & Matching identical passages & $\begin{array}{l}\text { Search engines such as Google, anti-plagiarism } \\
\text { software, and authors whose works are copied }\end{array}$ \\
\hline $\begin{array}{l}\text { Keywords and logical } \\
\text { words }\end{array}$ & Revealing semantic overlaps & $\begin{array}{c}\text { Search engines such as PubMed displaying similar } \\
\text { articles with overlapped keywords }\end{array}$ \\
\hline Writing styles & $\begin{array}{l}\text { Reporting mixed passages with American } \\
\text { and British English styles }\end{array}$ & Authors, readers, and editors \\
\hline Methodologies & $\begin{array}{l}\text { Distinguishing similarities in the sets } \\
\text { and order of tests }\end{array}$ & Authors, readers, and editors \\
\hline References & $\begin{array}{l}\text { Comparing similarities in the lists and order } \\
\text { of individual references }\end{array}$ & $\begin{array}{l}\text { Anti-plagiarism software, authors, readers, } \\
\text { and editors }\end{array}$ \\
\hline Hypotheses & $\begin{array}{c}\text { Comparing similarities and reporting episodes } \\
\text { of privileged exposure to unpublished } \\
\text { intellectual property }\end{array}$ & Authors, readers, and editors \\
\hline Graphics & $\begin{array}{c}\text { Visualization of identical or modified images, } \\
\text { tables, and figures }\end{array}$ & $\begin{array}{c}\text { Google Images engine and emerging advanced } \\
\text { anti-plagiarism software }\end{array}$ \\
\hline
\end{tabular}

of scholarly publications and lead to the so-called predatory practices [34, 35]. Generally, employing popular online platforms such as Google Scholar, Grammarly, and PlagScan makes it possible to improve the quality of references, readability, and linguistic style of scholarly manuscripts and increase their likelihood of acceptance by influential journals [36]. The role of processing manuscripts through freely available plagiarism detection tools is difficult to overestimate, since most researchers and faculty members, particularly in developing countries, lack access to proprietary software [37].

Preliminary evidence suggests that there are differences in the prevalence of textual plagiarism across academic disciplines, necessitating careful checks in science, technology, engineering, and mathematics journal submissions [38]. Additionally, in the era of digitization and open access, reviews are more likely to contain "copy-and-paste" written sections, pointing to the particular need for checks of this type of article [39].

Plagiarism detection and verification is largely based on text-matching search engines and computer software that report similarity scores. The advanced software is integrated with numerous publishers and online platforms to allow scanning of potential overlaps among countless open-access and subscription literature items [40]. Perhaps the most advanced anti-plagiarism system is iThenticate, which is employed by most established publishers to report the overall similarity score and similarity score from a single source [41]. The system offers options to filter direct quotations, bibliographies, and methodologies to minimize chances of erroneous reports [42]. High overall similarity scores (>35\%) often point to plagiarism requiring outright rejection or retraction [43].

Regular iThenticate checks have made it possible to minimize, but not exclude, unethical publications [44].
The reported similarity scores should not replace editorial decisions and should be accompanied by careful reading and validation of references [45].

Compared to textual similarity detection, image plagiarism detection is a more challenging task, since it often requires both image processing and semantic mapping techniques $[46,47]$. Google Images is a widely available search engine that can be used to reveal identical or manipulated images processed by Google [48]. However, this engine fails to detect copied and modified graphical materials. Semantic analyses are particularly useful in such a scenario of image modification. In fact, processing image legends through textual similarity tests may point to misconduct with modified images.

Attempts are underway to propose an advanced system for tracking plagiarism of graphics [49]. In the meantime, journal editors with a special interest in publishing graphics need to instruct their authors on what constitutes image plagiarism and how to ethically reuse related contents [50].

\section{Retractions due to plagiarism}

Although retractions of published articles are generally not frequent, their analyses may reveal countryand discipline-related differences in editorial strategies, misconduct prevention policies, and enforced measures [51, 52]. Examining details of retracted articles which are publicly discussed on the Retraction Watch blog may also prioritize ethics topics for postgraduate education [53, 54].

With the widespread use of iThenticate and other plagiarism detection software, numerous related retractions have taken place over the past decade. When retraction notices in PubMed are compared, similar percentages of plagiarism (about 20\%) were mentioned in 2008 and 2016 samples [55]. The number of retractions 
due to plagiarism varies across countries and academic disciplines, with the U.S., China, Germany, Japan and the U.K. accounting for 3 out of 4 retractions in a sample of 130 surgery articles [51]. The same study estimated a plagiarism rate of $16 \%$ in these articles. Also, an analysis of 176 retractions in obstetrics and gynecology indicated 40 cases of plagiarism (23\%) [56]. In rehabilitation and sport sciences, retractions due to plagiarism were reported in 11 (26\%) and 7 (13\%) cases, respectively [57]. And finally, an analysis of 22 rheumatology retractions revealed 7 (32\%) cases of plagiarism in review articles [58].

\section{Conclusions}

Plagiarism continues to affect the integrity of scholarly publications worldwide. Digitization and open access provide numerous opportunities for accessing and disseminating scientific information. However, some researchers and authors are tempted to intentionally or unintentionally embark on shortcuts and construct their articles with copied and unattributed texts, graphics, and ideas. Arguably, educating authors how to systematically access and process literature and how to master academic English may prevent most instances of modern-day plagiarism. Systematic searches are necessary for choosing new topics and avoiding redundancies. Processing retrieved articles, appropriately referring to published scientific facts, and writing in one's own words may further improve the ethical standing of new manuscripts.

Researchers and research managers alike need to learn more about globally acceptable writing practices, regularly analyze retractions due to plagiarism, and avoid related errors in their practice. Knowledge of global editorial guidance and plagiarism detection and prevention strategies is essential for successful writing and targeting influential ethical journals. Journal editors should enforce a "trust, but verify" policy by performing plagiarism checks, inquiring about authors' writing practices, and asking for disclaimers if suspicion of plagiarism persists.

The authors declare no conflict of interest.

\section{References}

1. Bouville M. Plagiarism: words and ideas. Sci Eng Ethics 2008; 14: 311-322, DOI: 10.1007/s11948-008-9057-6.

2. de Vasconcelos SM, Roig M. Prior Publication and Redundancy in Contemporary Science: Are Authors and Editors at the Crossroads? Sci Eng Ethics 2015; 21: 1367-1378, DOI: 10.1007/ s11948-014-9599-8.

3. Roig M. Avoiding unethical writing practices. Food Chem Toxicol 2012; 50: 3385-3387, DOI: 10.1016/j.fct.2012.06.043.

4. Wang T, Xing QR, Wang H, Chen W. Retracted Publications in the Biomedical Literature from Open Access Journals. Sci Eng Ethics 2019; 25: 855-868, DOI: 10.1007/s11948-018-0040-6.
5. Heaven D. Al peer reviewers unleashed to ease publishing grind. Nature 2018; 563: 609-610, DOI: 10.1038/d41586-018-07245-9.

6. Mehregan M. Ethical Reviewers are Essential for Scholarly Journals for Timely Processing of Submissions and Avoiding Retractions. J Korean Med Sci 2019; 34: e41, DOI: 10.3346/ jkms.2019.34.e41.

7. Yi N, Nemery B, Dierickx K. Perceptions of plagiarism by biomedical researchers: an online survey in Europe and China. BMC Med Ethics 2020; 21: 44, DOI: 10.1186/s12910-020-00473-7.

8. Core practices. Available from: https://publicationethics.org/ core-practices [Accessed 27.01.2021].

9. Misra DP, Agarwal V. Integrity of clinical research conduct, reporting, publishing, and post-publication promotion in rheumatology. Clin Rheumatol 2020; 39: 1049-1060, DOI: 10.1007/ s10067-020-04965-0.

10. CSE's White Paper on Promoting Integrity in Scientific Journal Publications. Available from: https://www.councilscienceeditors.org/wp-content/uploads/CSE-White-Paper_2018-update-050618.pdf [Accessed: 27.01.2021].

11. Recommendations on Publication Ethics Policies for Medical Journals. Available from: https://wame.org/recommendations-on-publication-ethics-policies-for-medical-journals\#Plagiarism [Accessed: 27.01.2021].

12. Gasparyan AY, Nurmashev B, Seksenbayev B, et al. Plagiarism in the Context of Education and Evolving Detection Strategies. J Korean Med Sci 2017; 32: 1220-1227, DOI: 10.3346/ jkms.2017.32.8.1220.

13. Sun $\mathrm{X}$, Hu G. What do academics know and do about plagiarism? An interview study with Chinese university teachers of English. Ethics Behav 2020; 30: 459-479, DOI: 10.1080/10508422.2019.1633922.

14. Masters K. Ethics in medical education digital scholarship: AMEE Guide No. 134. Med Teach 2020; 42: 252-265, DOI: 10.1080/0142159X.2019.1695043.

15. Coughlin PE. Plagiarism in five universities in Mozambique: Magnitude, detection techniques, and control measures. Int J Educ Integr 2015; 11: 2, DOI: 10.1007/s40979-015-0003-5.

16. Johnson DR, Ecklund EH. Ethical Ambiguity in Science. Sci Eng Ethics 2016; 22: 989-1005, DOI: 10.1007/s11948-015-9682-9.

17. Mahmud S, Bretag T, Foltýnek T. Students' Perceptions of Plagiarism Policy in Higher Education: a Comparison of the United Kingdom, Czechia, Poland and Romania. J Acad Ethics 2019; 17: 271-289, DOI: 10.1007/s10805-018-9319-0.

18. Javaeed A, Khan AS, Khan SH, Ghauri SK. Perceptions of plagiarism among undergraduate medical students in Rawalpindi, Pakistan. Pak J Med Sci 2019; 35: 532-536, DOI: 10.12669/ pjms.35.2.33.

19. Rokni MB, Bizhani N, Habibzadeh F, et al. Comprehensive Survey of Plagiarism in Iran. Pak J Med Sci 2020; 36: 1441-1448, DOI: 10.12669/pjms.36.7.3456.

20. Sharma H, Verma S. Insight into modern-day plagiarism: The science of pseudo research. Ci Ji Yi Xue Za Zhi 2019; 32: 240-244, DOI: 10.4103/tcmj.tcmj_210_19.

21. Das N. Intentional or unintentional, it is never alright to plagiarize: A note on how Indian universities are advised to handle plagiarism. Perspect Clin Res 2018; 9: 56-57, DOI: 10.4103/ picr.PICR_140_17.

22. Roig M. Encouraging Editorial Flexibility in Cases of Textual Reuse. J Korean Med Sci 2017; 32: 557-560, DOI: 10.3346/ jkms.2017.32.4.557. 
23. Vessal K, Habibzadeh F. Rules of the game of scientific writing: fair play and plagiarism. Lancet 2007; 369: 641, DOI: 10.1016/ S0140-6736(07)60307-9.

24. Ahmed S, Anirvan P. The true meaning of plagiarism. Indian J Rheumatol 2020; 15: 155-158, DOI: 10.4103/injr.injr_178_20.

25. Roostaee M, Fakhrahmad SM, Sadreddini MH. Cross-language text alignment: A proposed two-level matching scheme for plagiarism detection. Expert Syst Appl 2020; 160: 113718, DOI: 10.1016/j.eswa.2020.113718.

26. Memon AR. Similarity and Plagiarism in Scholarly Journal Submissions: Bringing Clarity to the Concept for Authors, Reviewers and Editors. J Korean Med Sci 2020; 35: e217, DOI: 10.3346/ jkms.2020.35.e217.

27. Baydik OD, Gasparyan AY. How to Act When Research Misconduct Is Not Detected by Software but Revealed by the Author of the Plagiarized Article. J Korean Med Sci 2016; 31 1508-1510, DOI: 10.3346/jkms.2016.31.10.1508.

28. Hong ST. Plagiarism Continues to Affect Scholarly Journals J Korean Med Sci 2017; 32: 183-185, DOI: 10.3346/jkms.2017. 32.2.183.

29. Zhang XX, Huo ZL, Zhang YH. Detecting and (not) dealing with plagiarism in an engineering paper: beyond CrossCheck a case study. Sci Eng Ethics 2014; 20: 433-443, DOI: 10.1007/ s11948-013-9460-5.

30. Misra DP, Ravindran V. Publication misconducts related to copyright: tread carefully to avoid falling. J R Coll Physicians Edinb 2020; 50: 3-5, DOI: 10.4997/JRCPE.2020.101.

31. Kravitz RL, Feldman MD. From the Editors' Desk: Self-Plagiarism and Other Editorial Crimes and Misdemeanors. J Gen Intern Med 2011; 26: 1, DOI: 10.1007/s11606-010-1562-z.

32. Park S, Yang SH, Jung E, et al. Similarity Analysis of Korean Medical Literature and Its Association with Efforts to Improve Research and Publication Ethics. J Korean Med Sci 2017; 32 887-892, DOI: 10.3346/jkms.2017.32.6.887.

33. Foltýnek T, Dlabolová D, Anohina-Naumeca A, et al. Testing of support tools for plagiarism detection. Int J Educ Technol High Educ 2020; 17: 46, DOI: 10.1186/s41239-020-00192-4.

34. Owens JK, Nicoll LH. Plagiarism in Predatory Publications: A Comparative Study of Three Nursing Journals. J Nurs Scholarsh 2019; 51: 356-363, DOI: 10.1111/jnu.12475.

35. Paltridge B. Writing for Academic Journals in the Digital Era RELC J 2020; 51: 147-157, DOI: 10.1177/0033688219890359.

36. Magulod GC, Capulso LB, Tabiolo CDL, et al. Use of technologybased tools in ensuring quality of publishable journal articles. Int J Learn Teach Educ Res 2020; 19: 145-162.

37. Memon AR, Mavrinac M. Knowledge, Attitudes, and Practices of Plagiarism as Reported by Participants Completing the Author AID MOOC on Research Writing. Sci Eng Ethics 2020; 26 1067-1088, DOI: 10.1007/s11948-020-00198-1.

38. Sun YC. Do journal authors plagiarize? Using plagiarism detection software to uncover matching text across disciplines J Engl Acad Purp 2013; 12: 264-272, DOI: 10.1016/jeap. 2013.07.002.

39. Baskaran S, Agarwal A, Panner Selvam MK, et al. Is there plagiarism in the most influential publications in the field of andrology? Andrologia 2019; 51: e13405, DOI: 10.1111/and.13405.

40. Li Y. Text-based plagiarism in scientific publishing: issues, developments and education. Sci Eng Ethics 2013; 19: 1241-1254, DOI: 10.1007/s11948-012-9367-6.

41. Taylor DB. Plagiarism in Manuscripts Submitted to the AJR: Development of an Optimal Screening Algorithm and Manage- ment Pathways. AJR Am J Roentgenol 2017; 208: 712-720, DOI: 10.2214/AJR.17.18078

42. Miller BJ. Similarity scores are not all the same. J Psychiatr Res 2020; 131: 31-32.

43. El-Tahan MR. Can the similarity index predict the causes of retractions in high-impact anesthesia journals? A bibliometric analysis. Saudi J Anaesth 2019; 13 (Suppl 1): S2-S8, DOI: 10.4103/sja.SJA_709_18.

44. Park S, Yang SH, Jung E, et al. Similarity Analysis of Korean Medical Literature and Its Association with Efforts to Improve Research and Publication Ethics. J Korean Med Sci 2017; 32: 887-892, DOI: 10.3346/jkms.2017.32.6.887.

45. Weber-Wulff D. Plagiarism detectors are a crutch, and a problem. Nature 2019; 567: 435, DOI: 10.1038/d41586-019-00893-5.

46. Shen $\mathrm{H}$. Meet this super-spotter of duplicated images in science papers. Nature 2020; 581: 132-136, DOI: 10.1038/d41586020-01363-z.

47. Eisa TAE, Salim N, Abdelmaboud A. Content-based scientific figure plagiarism detection using semantic mapping. In: Saeed F, Mohammed F, Gazem N (eds.). Emerging Trends in Intelligent Computing and Informatics. IRICT 2019. Advances in Intelligent Systems and Computing 2020; 1073: 420-427. Springer, Cham, https://doi.org/10.1007/978-3-030-33582-3 40.

48. Thakur R, Rohilla R. Recent advances in digital image manipulation detection techniques: A brief review. Forensic Sci Int 2020; 312: 110311, DOI: 10.1016/j.forsciint.2020.110311.

49. Akshay S, Chaitanya BN, Kumar R. Image plagiarism detection using compressed images. IJITEE 2019; 8: 1423-1426.

50. Kaliyadan F. Image manipulation and image plagiarism what's fine and what's not? Indian J Dermatol Venereol Leprol 2017; 83: 519-521, DOI: 10.4103/ijdvl.IJDVL 52117.

51. Cassão BD, Herbella FAM, Schlottmann F, Patti MG. Retracted articles in surgery journals. What are surgeons doing wrong? Surgery 2018; 163: 1201-1206, DOI: 10.1016/j.surg.2018.01.015.

52. Ayodele FO, Yao L, Haron H. Promoting Ethics and Integrity in Management Academic Research: Retraction Initiative. Sci Eng Ethics 2019; 25: 357-382, DOI: 10.1007/s11948-017-9941-z.

53. Kamali N, Talebi Bezmin Abadi A, Rahimi F. Plagiarism, Fake Peer-Review, and Duplication: Predominant Reasons Underlying Retractions of Iran-Affiliated Scientific Papers. Sci Eng Ethics 2020; 26: 3455-3463, DOI: 10.1007/s11948-020-00274-6.

54. Rossouw TM, Matsau L, van Zyl C. An Analysis of Retracted Articles with Authors or Co-authors from the African Region: Possible Implications for Training and Awareness Raising. J Empir Res Hum Res Ethics 2020; 15: 478-493, DOI: 10.1177/1556264620955110.

55. Decullier E, Maisonneuve H. Correcting the literature: Improvement trends seen in contents of retraction notices. BMC Res Notes 2018; 11: 490, DOI: 10.1186/s13104-018-3576-2

56. Chambers LM, Michener CM, Falcone T. Plagiarism and data falsification are the most common reasons for retracted publications in obstetrics and gynaecology. BJOG 2019; 126: 11341140, DOI: 10.1111/1471-0528.15813.

57. Kardeş S, Levack W, Özkuk K, et al. Retractions in Rehabilitation and Sport Sciences Journals: A Systematic Review. Arch Phys Med Rehabil 2020; 101: 1980-1990, DOI: 10.1016/j.apmr. 2020.03.010.

58. Gasparyan AY, Ayvazyan L, Akazhanov NA, Kitas GD. Self-correction in biomedical publications and the scientific impact. Croat Med J 2014; 55: 61-72, DOI: 10.3325/cmj.2014.55.61. 